\title{
Ventilatory Chemoreceptor Response in Parents of Children at Risk for Sudden Infant Death Syndrome
}

\author{
DAVID J. KANAREK, DOROTHY H. KELLY, AND DANIEL C. SHANNON ${ }^{(31)}$ \\ Pulmonary Unit, Department of Medicine, Massachusetts General Hospital and the Pediatric Pulmonary Unit, \\ Children's Service, Massachusetts General Hospital and Departments of Medicine and Pediatrics, Harvard Medical \\ School, Boston, Massachusetts, USA
}

\begin{abstract}
Summary
We postulated that parents of infants who sustain near-death episodes associated with defective chemical regulation of breathing might share a similar defect. We, therefore, measured the ventilatory responses to progressive hypoxia and hypercapnia individually in eight sets of parents of infants who had sustained at least one near-death episode (apnea, cyanosis, pallor, limpness, and responsive only to mouth-to-mouth resuscitation); each infant had a ventilatory response to $\mathrm{CO}_{2}$ which was more than 2 S.D. below the mean normal. Ventilatory function measured by vital capacity forced expiratory volume 1.0 and flow volume curves was normal in each group. Responses to hypercapnia and hypoxemia in both fathers and mothers were similar to 11 pairs of controls. Ventilation during $\mathrm{CO}_{2}$ rebreathing normalized for surface area increased $0.87 \mathrm{liter} / \mathrm{min} / \mathrm{mm} \mathrm{Hg}$ in fathers, $0.94 \mathrm{in} \mathrm{controls,} 0.87 \mathrm{in}$ mothers, and 0.75 in controls. Ventilation during progressive hypoxemia
\end{abstract} increased $88 \mathrm{liter} / \mathrm{min} / \frac{1}{\mathrm{~mm} \mathrm{Hg}}$ in fathers, 92 in controls, 86 in mothers, and 101 in controls. None of these differences was significant.

\section{Speculation}

Defective chemical regulation of breathing in infants at risk of sudden infant death syndrome is not shared by their parents. This suggests that environmental influences, perhaps in utero, are responsible for this defect.

Evidence has slowly accrued in the literature suggesting that sudden infant death syndrome (SIDS) may, in some cases, be associated with abnormal control of ventilation. Prolonged apnea has been seen before death in some subjects $(10,22,24)$. Near fatal chronic sleep hypoventilation from severe $(8,21)$ to mild $(20)$ has been documented in other subjects who lacked an appropriate ventilatory response to carbon dioxide breathing. Periodic breathing resembling Cheyne-Stokes respiration has been found in a higher than normal percentage of sleep time in these infants (11). A reduced ventilatory response to hypoxia has also been documented by others (2). Among the 11 infants with prolonged sleep apnea and chronic hypoventilation previously reported (20), four were in families who previously or subsequently had one or more infants with a similar syndrome. Familial sleep apnea syndrome has been associated with sudden death in both adults and infants (25). Genetic influences on breathing control have been reported in the past in endurance athletes (19), twins $(2,7)$, and subjects with idopathic hypoventilation (12). Causes of hypoventilation and hypoxia, distinct from effects, have thus far eluded description. Two recent reports present data that support opposing conclusions regarding genetic influences on ventilatory control in
SIDS $(18,30)$. We, therefore, measured the ventilation chemosensitivity to carbon dioxide and to hypoxia in parents of infants who had previously experienced a near sudden death and had blunted carbon dioxide ventilatory responses. We selected this group of infants and their parents to exclude other causes of SIDS.

\section{MATERIALS AND METHODS}

\section{SUBJECTS}

Two groups of subjects were chosen. The first group consisted of eight sets of parents, each of whom had previously had one infant who suffered from the "near-miss" syndrome, and each infant had been documented to have reduced ventilatory response to carbon dioxide breathing and an elevated alveolar $\mathrm{PCO}_{2}$ measured during quiet sleep. These infants were drawn from the original study which had documented this response (20). In each infant, the ventilatory response to $\mathrm{CO}_{2}$ was more than 2. S.D. below the mean normal level measured in quiet sleep. It might be questioned whether these infants who sustained near-death episodes represent those whose diagnosis of SIDS is made at autopsy. We believe that they do represent one cause of SIDS because three of those in our original study died and were classified SIDS at autopsy because they lacked an apparent explanation for death (22). In addition, on careful morphometric analysis of the lung we found that they shared muscular hyperplasia of small pulmonary arteries (23) with other infants who died of SIDS $(14,28)$.

The parents were selected only on the grounds of their availability for the study. The second, a control group of 11 males and 11 females, was matched with the parents for age and sex. Informed consent was obtained according to the guidelines of the Human Studies Committee, Massachusetts General Hospital. Heights and weights were comparable for males and females (Table 1). None of the 12 children born to control subjects died of SIDS.

All subjects carried out the same procedure at the same time of day seated and awake. Their last meal was at least $3 \mathrm{hr}$ before the study began; they had not abstained from coffee, tea, or cigarettes except for this 3-hr period. Among parents of near-miss infants, there were five who smoked more than one pack per day; three of these were females. Among controls, two smoked more than one pack per day, and one female smoked less than one pack per day. One female parent of a near-miss infant admitted to taking one diazepam the day before study; one male control took dramamine the day before study (Table 2).

We measured vital capacity, forced expiratory volume (1.0), peak expiratory flow, maximum midexpiratory flow, and flow at $25 \%$ of vital capacity from the subject's best effort during three flow volume determinations using a wedge spirometer. We then measured a single ventilatory response to $\mathrm{CO}_{2}$ by having the subject rebreath from a 5 -liter bag of $5 \% \mathrm{CO}_{2}$ in $95 \% \mathrm{O}_{2}(16)$. One 
Table 1.

\begin{tabular}{|c|c|c|c|c|}
\hline & \multicolumn{2}{|c|}{ Near miss } & \multicolumn{2}{|c|}{ Control } \\
\hline & Male & Female & Male & Female \\
\hline Age (yr) & $30.8(24-36)^{l}$ & $29.9(24-36)$ & $31(24-38)$ & $30.2(24-38)$ \\
\hline Height $(\mathrm{cm})$ & $182.4(173-198)$ & $160.8(151-174)$ & $179.9(168-191)$ & $164(161-174)$ \\
\hline Weight (kg) & $85.4(59-100)$ & $58.6(48-66)$ & $77.4(61-90)$ & $57.4(53-67)$ \\
\hline
\end{tabular}

${ }^{1}$ Mean (range).

Table 2

\begin{tabular}{|c|c|c|c|c|}
\hline & \multicolumn{2}{|l|}{ Male } & \multicolumn{2}{|c|}{ Female } \\
\hline & Near-miss & Control & Near-miss & Control \\
\hline \multicolumn{5}{|l|}{ Smoking } \\
\hline$\geq 1 \mathrm{pack} / \mathrm{day}$ & 2 & 1 & 3 & 1 \\
\hline$<1 \mathrm{pack} / \mathrm{day}$ & 1 & 0 & 0 & 1 \\
\hline Medication & 1 (dramamine $)$ & 0 & 1 (valium) & 0 \\
\hline
\end{tabular}

hr later, we measured a single ventilatory response to hypoxia using a rebreathing technique in which subjects began by breathing a mixture of $21 \% \mathrm{O}_{2}$ and $5 \% \mathrm{CO}_{2}$ from a 6-liter bag. The $\mathrm{PO}_{2}$ was monitored continuously by drawing $200 \mathrm{ml} / \mathrm{min}$ of expired gas through an $\mathrm{O}_{2}$ and $\mathrm{CO}_{2}$ analyzer (Beckman Instruments, Fullerton, $\mathrm{CA}$ ). The end-tidal $\mathrm{PCO}_{2}$ was maintained at each individual's arterial $\mathrm{PCO}_{2}$ by varying the flow of expired gas through a carbon dioxide absorber in a circuit parallel to the flow of expired gas. Arterial $\mathrm{PCO}_{2}$ was estimated by subtracting $6 \mathrm{~mm} \mathrm{Hg}$ from the mixed venous $\mathrm{PCO}_{2}$ measured by the Collier and Campbell rebreathing technique. The response to carbon dioxide breathing was expressed as the slope of the relationship between the change in minute ventilation and the change in alveolar $\mathrm{PCO}_{2}$ over the range between mixed venous $\mathrm{PCO}_{2}$ and an arbitrary end point of $60 \mathrm{~mm} \mathrm{Hg}$. The slope of the response is linear using this technique. The response to hypoxia was expressed as expired ventilation/liter $/\left(\mathrm{PaO}_{2}-32 \mathrm{~mm} \mathrm{Hg}\right)(17)$ where the usual hyperbolic response of minute ventilation to hypoxia is transformed into a linear function by taking the reciprocal value of the hypoxic stimulus. We chose the value for $\dot{\mathrm{VE}}$ corresponding to $\mathrm{PaO}_{2} 40$ $\mathrm{mm} \mathrm{Hg}$ in each subject; this usually occurred after 4 to $5 \mathrm{~min}$. Data were sampled on line, digitized, and analyzed by computer to avoid bias. For both the ventilatory response to hypercapnia and to hypoxia, we chose to compare the means of single responses per subject as values representative of each group's response rather than multiple responses per subject which better reflect an individual's response (1). Measured values were divided by surface area and by vital capacity to permit better intergroup comparisons. The significance of differences between groups means was determined by Student's one-tailed $t$ test.

\section{RESULTS}

There were no significant differences in vital capacity, forced expiratory volume 1.0, and other indices of air flow obstruction in fathers and mothers of near-miss infants and their respective controls (Table 3 ).

During $\mathrm{CO}_{2}$ rebreathing (Table 4) ventilation increased 0.87 liters $/ \mathrm{min} / \mathrm{mm} \mathrm{Hg} \mathrm{PCO} / \mathrm{M}^{2}$ (S.D., 0.28) in male parents and 0.94 (S.D., .20) in controls (not significant). Similarly, in mothers, ventilation increased $0.87 \mathrm{liter} / \mathrm{min} / \mathrm{mm} \mathrm{Hg} \mathrm{PCO} / \mathrm{M}^{2}(0.28)$ and $0.75(0.20)$ in controls (not significant). Ventilation during hypoxia increased $88 \mathrm{liter} / \mathrm{min} / \frac{1 / \mathrm{M}^{2}}{\mathrm{~mm} \mathrm{Hg}}$ in fathers and 92 in controls (not significant). Ventilation during hypoxia in mothers of near-miss infants increased 86 compared to $101 \mathrm{liter} / \mathrm{min} / \frac{1 / \mathrm{M}^{2}}{\mathrm{~mm} \mathrm{Hg}}$ (not significant). Thus, we found no group differences in either mothers or fathers of near-miss SIDS infants compared to age- and sexmatched controls. In one family, there were three near-miss infants, two of whom subsequently died of SIDS. In two of these infants, the ventilatory response to $\mathrm{CO}_{2}$ was below 2 S.D. of the mean for normal infants. The ventilatory responses of both parents to both hypercapnia and hypoxia were high in the normal range.

\section{DISCUSSION}

Naeye (15) and Cole et al. (5), have both suggested that the structure of carotid bodies taken from infants who died of SIDS is abnormal; Cole et al. believed that there was a reduction in the cytoplasmic granules of chemoreceptor cells. Naeye (13) and Takashima et al. (26) have both observed excess astrogilial proliferation in the region of brain stem projection of carotid body afferent chemoreceptor impulses (9) and around other brain stem nuclei involved in mediation of cardiorespiratory control. These data and those from several other laboratories support the conclusion that many SIDS infants die of a defect in regulation of the respiratory and cardiovascular systems.

Although the index child in each family had a documented low response to $\mathrm{CO}_{2}$ breathing, this response was normal in both parents. Unfortunately, hypoxic responses were not measured at the time these near-miss infants were studied. However, we have subsequently identified marked attenuation of both the hypoxic response and the hypercapnic response in other infants with severe sleep hypoventilation (8) that may also cause sudden death. It is likely that repeated hypoxia during hypoventilation leads to brain stem gliosis as identified by Naeye (13) and by Takashima et al. (26) in several groups of infants with repeated hypoxia. This secondary defect might then promote a positive feedback loop in which hypoxia begets further hypoxia. Alternatively, the findings could be explained by a defect in central integration of chemoreceptor afferents. Chronic hypoxemia, occurring in children with cyanotic congenital heart disease (4) and in normal man at high altitude (27), is also associated with somewhat depressed hypercapnic ventilatory drive as well as reduced hypoxic drive and a similar degree of brain stem gliosis (26).

There are several familial situations in which the ventilatory responses to hypoxia and hypercapnia are abnormal: otherwise normal family members of patients with unexplained hypoventilation (12) as well as athletes $(3,19)$ and their nonathletic family members (19). Also, a correlation of the hypoxic responses has been demonstrated in identical but not in nonidentical twins $(6$, 29). However, our data do not suggest that defective chemoreceptor control of breathing is aggregated in families of infants at risk of SIDS.

To circumvent confounded results due to multiple causes of near-miss SIDS, we selected only parents of infants whose ventilatory responses to $\mathrm{CO}_{2}$ breathing were blunted. Thus, our data and those of others may not represent entirely comparable groups of subjects. Nevertheless, the slopes of ventilatory responses to $\mathrm{CO}_{2}$ breathing in both our controls and near-miss parents are similar to those of Zwillich et al. (30) when all data are expressed in the same units (Table 5). However, the slopes of hypoxic ventilatory responses differ; the mean value in our controls is higher than their controls and, in fact, is close to the value in their near-miss parents. These differences may reflect variations in subject selection or in methodology. Although their determination of isocapnic responses should have yielded a systematic increase 
Table 3. Ventilatory tests

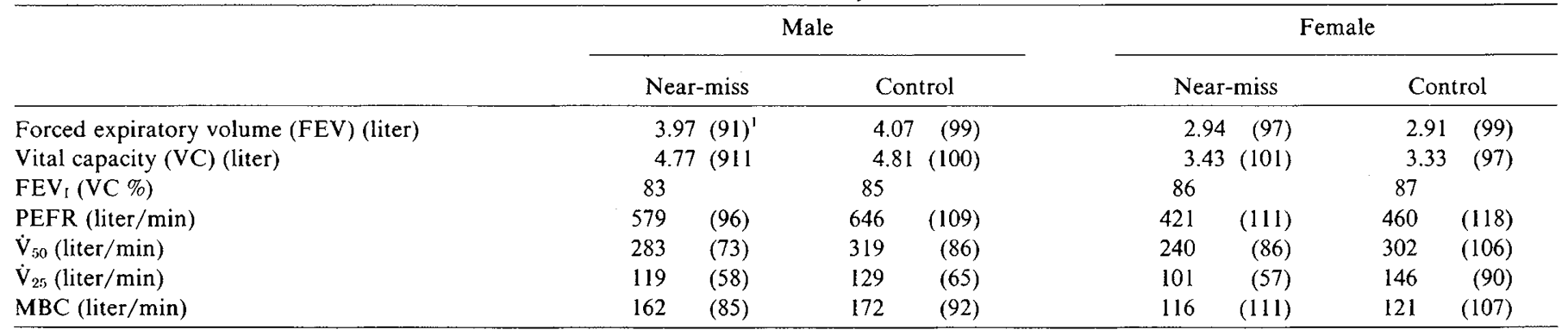

${ }^{\prime}$ Numbers in parentheses are percentage predicted.

Table 4.

\begin{tabular}{lcc}
\hline & $\begin{array}{c}\mathrm{CO}_{2} \text { response } \\
(\text { liter } / \mathrm{min} / \mathrm{mm} \mathrm{Hg} \mathrm{CO}) \\
\left(\mathrm{M}^{2}\right)\end{array}$ & $\begin{array}{c}\mathrm{O}_{2} \text { response } \\
\left.\text { liter } / \mathrm{m} / \frac{1}{\mathrm{~mm} \mathrm{Hg}} / \mathrm{M}^{2}\right)\end{array}$ \\
\hline Male parents & $0.87 \pm 0.28$ & $88 \pm 39$ \\
Male controls & $0.94 \pm 0.20$ & $92 \pm 38$ \\
Female parents & $0.87 \pm 0.28$ & $86 \pm 75$ \\
Female controls & $0.75 \pm 0.20$ & $101 \pm 62$ \\
\hline
\end{tabular}

Table 5.

\begin{tabular}{|c|c|c|c|c|c|c|}
\hline & \multicolumn{3}{|c|}{$\begin{array}{l}\text { Slope of hypercapnic } \\
\text { response } \\
\left(\text { liter } / \mathrm{m} / \mathrm{mm} \mathrm{Hg} / \mathrm{M}^{2}\right)\end{array}$} & \multicolumn{3}{|c|}{$\begin{array}{l}\text { Slope of hypoxic response } \\
\left(\text { liter } / \mathrm{m} / \frac{1}{\mathrm{~mm} \mathrm{Hg}} / \mathrm{M}^{2}\right)\end{array}$} \\
\hline & Males & Females & $\begin{array}{l}\text { Males } \\
\text { and } \\
\text { females }\end{array}$ & Males & Females & $\begin{array}{l}\text { Males } \\
\text { and } \\
\text { females }\end{array}$ \\
\hline \multicolumn{7}{|l|}{$\begin{array}{l}\text { Zwillich et al. } \\
\text { (30) }\end{array}$} \\
\hline Control & & & 1.08 & & & 57 \\
\hline Near-miss & & & 1.10 & & & 79 \\
\hline SIDS & & & 1.12 & & & 73 \\
\hline \multicolumn{7}{|l|}{$\begin{array}{r}\text { Shannon and } \\
\text { Kanarek }\end{array}$} \\
\hline Control & 0.94 & 0.75 & 0.86 & 92 & 101 & 97 \\
\hline Near-miss & 0.83 & 0.86 & 0.85 & 88 & 86 & 87 \\
\hline \multicolumn{7}{|c|}{$\begin{array}{l}\text { Schiffman et al. } \\
\text { (18) }\end{array}$} \\
\hline $\begin{array}{l}\text { Control } \\
\text { SIDS }\end{array}$ & & & 1.31 & 0.84 & & \\
\hline
\end{tabular}

in hypoxic response compared to our method which permitted hypocapnic depression, such a difference was not apparent. Our results can not be fully compared to those of Schiffman et al. (18) who studied $\mathrm{CO}_{2}$ ventilatory responses in parents of SIDS victims; however, it can be seen that the average of their unloaded $\mathrm{CO}_{2}$ responses in SIDS parents is comparable to that of our controls.

In conclusion, we have found that the ventilatory responses to hypercapnia and hypoxia were normal in parents whose infants manifest blunted responses to hypercapnia. The defect in infants is more probably explained by environmental than by genetic influences.

\section{REFERENCES AND NOTES}

1. Arkinstall, W. W., Nirmel, K., Klissouras, V., and Milic-Emili, J.: Genetic differences in the ventilatory response to inhaled $\mathrm{CO}_{2}$. J. Appl. Physiol., 36: 6 (1974).

2. Brady, J. P., Areagno, R. L., Watts, J. L., Goldman, S. H., and Dumpit, F. M.:
Apnea, hypoxemia, and aborted sudden infant death syndrome. Pediatrics, 62: $686(1978)$.

3. Bryne-Quinn, E., Weil, J. V., Sodal, I. E., Filley, G. F., and Grover, R. F.: Ventilatory control in the athlete. J. Appl. Physiol., 30: 91 (1971).

4. Cherniak, N. S., Edelman, N. H., and Lahiri, S.: Hypoxia and hypercapnia as respiratory stimulants and depressants. Respir. Physiol., 11: 113 (1970).

5. Cole, S., Lindenberg, L. B., Galioto, F., et al: Ultrastructural abnormalities of the carotid body in sudden infant death syndrome. Pediatrics, 63: 13 (1979).

6. Collins, D., Scoggin, C. H., Zwillich, C. W., et al.: Genetic factors in the control of breathing. Clin. Res., 25: 132A (1977).

7. Collins, D., Scoggin, C. H., Zwillich, C. W., and Weil, J. V.: Hereditary aspects of decreased hypoxic response. J. Clin. Invest., 62: 107 (1978).

8. Custer, J. R., Kelly, D. H., and Shannon, D. C.: Pathophysiology of chemoreceptor function in congenital hypoventilation syndrome. Am. Rev. Respir. Dis. (Abstract), 119: 266 (1979).

9. Davies, R. O., and Edward, M. W.: Medullary relay neurons in the carotid body chemoreceptor pathway of cats. Respir. Physiol., 24:69 (1979).

10. Guilleminault, C., Peraita, R., Couget, M., and Dement, W. C.: Apnea during sleep in infants possible relationship with sudden infant death syndrome. Science (Wash. D. C.), 190: 677 (1975).

11. Kelly, D. H., and Shannon, D. C.: Periodic breathing in infants with near-miss sudden infant death syndrome. Pediatrics 63: 355 (1979).

12. Moore, L. G., Zwillich. C. W., Battagilia, J., Cotton, E. K., and Weil, J. V.: Respiratory failure associated with familial depression of ventilatory response to hypoxia and hypercapnia. N. Engl. J. Med., 295: 861 (1976).

13. Naeye, R. L.: Brainstem and adrenal abnormalities in the sudden infant death syndrome. Am. J. Clin. Pathol., 66: 526 (1976).

14. Naeye, R. L.: Pulmonary arterial abnormalities in the sudden infant death syndrome. N. Engl. J. Med., 289: 1167 (1973).

15. Naeye, R. L.: Hypoxemia and the sudden infant death syndrome. Science (Wash. D. C.), 186: 837 (1974).

16. Read, D. J. C.: A clinical method of assessing the ventilatory response to carbon dioxide. Aust. Ann. Med., 16: 20 (1967).

17. Rebuck. A. S., and Campbell, E. J. M.: A clinical method for assessing the ventilatory response to hypoxia. Am. Rev. Respir. Dis., 109: 345 (1974).

18. Schiffman, P. L., Westlake, R. E., Somtiago, T. V., and Edelman, N. H.: Ventilatory control in parents of victims of sudden-infant death syndrome. $\mathrm{N}$. Engl. J. Med., 302: 486 (1980).

19. Scoggin, C. H., Doekel, R. D., Kryger, M. H., Zwillich, C. N., and Weil, J. V.: Familial aspects of decreased hypoxic drive in endurance athletes. J. Appl. Physiol., 44: 464 (1978).

20. Shannon, D. C., Kelly, D. H., and O'Connell, K.: Abnormal regulation of ventilation in infants at risk for sudden infant death syndrome. N. Engl. J. Med., 297: 747 (1977)

21. Shannon, D. C., Marsland, D. W., Gould, J. B., Callahan, B., Todres, I. D., and Dennis, J.: Central hypoventilation during quiet sleep in two infants. Pediatrics, 57: 342 (1976).

22. Shannon, D. C., and Kelly, D. H.: Impaired regulation of alveolar ventilation and the sudden infant death syndrome. Science (Wash. D. C.), 197: 367 (1977).

23. Shannon, D. C., Rabinovitch, M., Williams, A. J., Kelly, D. H., and Reid, L.: Pulmonary vascular muscle hyperplasia associated with impaired ventilation in SIDS. Am. Rev. Respir. Dis. (Abstract), 121: 419 (1980).

24. Steinschneider, A.: Prolonged apnea and the sudden infant death syndrome: Clinical and laboratory observation. Pediatrics, 50: 636 (1972).

25. Strohl, K. P., Saunders, N. A., Feldman, N. T., and Hallet, M.: Obstructive sleep apnea in family members. N. Engl. J. Med., 299: 969 (1978).

26. Takashima, S., Armstrong, D., Becker, L., and Bryan, C.: Cerebral hypoperfusion in the sudden infant death syndrome: brain stem gliosis and vasculature. Ann. Neurol., 4: 257 (1978).

27. Weil, J. V., Byrne-Quinn, E., Sodal, I. E., Filley, G. F., and Grover, R. F.: Acquired attenuation of chemoreceptor function in chronically hypoxic man at high altitude. J. Clin. Invest., 50: 186 (1971).

28. Williams, A., Vawter, G., and Reid, L.: Increased pulmonary artery muscularity in victims of the sudden infant death syndrome (SIDS). Pediatrics, 63: 18 (1979).

29. Yawakami, Y., Yoshikawa, Y., Kamishma, K., Yamamotok, K., and Murao, M.: Chemical mechanical control of breathing in twins. Am. Rev. Respir. Dis. (Abstract), 121: 360 (1980). 
30. Zwillich, C., McCullough, R., Guilleminault, C., Cummiskey, J., and Weil, J. V.: Respiratory control in the parents of sudden infant death syndrome victims; ventilatory control in SIDS parents. Pediatr. Res., 14: 762 (1980).

31. Requests for reprints should be addressed to: Daniel C. Shannon, M.D. Pediatric Pulmonary Research Unit, Massachusetts General Hospital, Boston, MA 02114

Copyright (C) 1981 International Pediatric Research Foundation, Inc. $0031-3998 / 8 \mathrm{I} / \mathrm{I} 511-1402 \$ 02.00 / 0$
(USA).

32. This research was supported by Grant ROIHD11965 from the National Institutes of Health, Bethesda, MD.

33. Received for publication July 15, 1980

34. Accepted for publication March 26, 1981.

January $15-17$, 1982-SYMPOSIUM ON MIDDLE CHILDHOOD: DEVELOPMENTAL VARIATION AND DYSFUNCTION BETWEEN SIX AND FOURTEEN YEARS will take place at the Hyatt-Regency New Orleans, in New Orleans, LA. Co-Sponsored by the Institute for Pediatric Service of the Johnson \& Johnson Baby Products Company; The Division of Ambulatory Pediatrics, The Children's Hospital Medical Center, Boston, MA; and the Neuropsychiatric Institute, UCLA, Los Angeles, CA. Symposium Co-Chairmen: Melvin D. Levine, M.D. and Paul Satz, Ph.D. Appropriate Category l CME Credíts toward the American Medical Association Physician's Recognition Award and the American Academy of Pediatrics PREP Required Credits will be given. For further information contact: Steven Sawchuk, M.D., Johnson \& Johnson Baby Products Co., Grandview Road, Skillman, NJ 08558 (201) 874-1645 or 1646. 